Original article

\title{
CHANGES IN CLINICAL AND BLOOD LIPID METABOLISM PARAMETERS IN HOLSTEIN DAIRY CATTLE DURING THE TRANSITION PERIOD
}

\author{
A. KHALPHALLAH ${ }^{1}$, A. A. AAMER ${ }^{1}$, T. ABDELALL ${ }^{1}$, E. ELMELIGY ${ }^{2}$, \\ S. OIKAWA ${ }^{3} \&$ K. NAKADA ${ }^{3}$ \\ ${ }^{1}$ Department of Animal Medicine, Faculty of Veterinary Medicine, Assiut \\ University, Egypt; ${ }^{2}$ Veterinary Teaching Hospital, Faculty of Veterinary \\ Medicine, Assiut University, Egypt; ${ }^{3}$ Department of Veterinary Herd Health, \\ School of Veterinary Medicine, Rakuno Gakuen University, Ebetsu, Japan
}

\section{Summary}

Khalphallah, A., A. A. Aamer, T. AbdelAll, E. Elmeligy, S. Oikawa \& K. Nakada, 2018. Changes in clinical and blood lipid metabolism parameters in Holstein dairy cattle during the transition period. Bulg. J. Vet. Med., 21, No 4, 420-428.

The transition period is a critical period in the production cycle of the dairy cow. This study aimed to describe the clinical and biochemical changes, particularly lecithin: cholesterol acyltransferase (LCAT) and apolipoprotein B-100 (ApoB-100), during the transition period in dairy cattle. It was conducted on Holstein dairy cattle $(n=80)$ classified into control cows $(n=61)$ and diseased cows $(\mathrm{n}=19)$. They belonged to dairy farms in Ebetsu city, Hokkaido area, Japan. Body condition score (BCS) was significantly reduced in postfresh control cows when they were compared to those of close-up control group. Serum LCAT and apoB-100 were remarkably increased $(\mathrm{P}<0.05)$ at close-up period control group when they compared with those in close-up period diseased one. LCAT activities were also remarkably increased $(\mathrm{P}<0.05)$ while apoB-100 showed no significant changes at postfresh control cattle when they were compared to their values at post-fresh diseased cattle. Although apoB-100 was within the normal physiological reference values in the control and diseased cattle, it was lower than physiological reference values in $9.83 \%$ of the control cattle and in $26.32 \%$ of the diseased group. Blood glucose and packed cell volume were still within the physiological reference range in all cows. The study concluded that LCAT activities were a highly sensitive diagnostic marker of the transition period and of higher predictive value and diagnostic significance than the other lipid profile indicators of transition period disorders.

Key words: dairy cattle, fat metabolism, lecithin:cholesterol acyltransferase, transition period

\section{INTRODUCTION}

The management of the transition period of dairy cows from 3 weeks before parturition to 3 weeks postpartum is aimed at optimisation of animal health and productivity (Cook \& Nordlund, 2004). The metabolic diseases are of greatest 
importance in dairy cows and pregnant ewes. In the other species, these diseases occur only sporadically. The high-producing dairy cow always verges on abnormal homeostasis as well as their breeding and feeding for high milk yields is etiologically associated with metabolic disease so common in these animals (Corohn, 1998; Radostits et al., 2007).

Lipid metabolism is the key of transition cows biology (Drackley, 1999). Excessive lipolysis from adipose tissue is associated with greater incidences of periparturient diseases. Fatty livers have been reported in ketotic cows in the 1950s. Fatty liver infiltration was then noted in normal cows during early lactation. Later on, a fat mobilization syndrome in early lactation was described in cows, in which cows mobilized body lipids from adipose tissue and deposited lipids in the liver, muscle, and other tissues (Cameron et al., 1998; LeBlanc et al., 2005).

Elevated non esterified fatty acids (NEFAs) concentrations during the last 7 days before calving have been associated with a greater incidence of the three energy related diseases; ketosis, displaced abomasum (DA) and retained placenta but not milk fever (Cameron et al., 1998; LeBlanc et al., 2005).

Many studies focused on the clinical and biochemical changes during transition period in dairy cows describing changes in blood NEFA (LeBlanc et al., 2005), glucose (Yameogo et al., 2008; Mokhber Dezfouli et al., 2013), total protein (Yameogo et al., 2008), $\beta$-hydroxybutyric acid (BHBA) (Sakha et al., 2006) either in healthy cows or in cows with periparturient diseases.

Recently, the lipid profile has been reported an important indicator in heifers and cows. According to our knowledge, the serum biochemical changes of lecithin:cholesterol acyltransferase (LCAT) and apolipoprotein B-100 (apoB-100) in transition cows were not widely assessed in periparturient diseases in cattle disturbing the productivity of the herds. Diseases of periparturient period such as ketosis, DA and retained placenta mainly are associated with fatty liver. They also cause loss of milk production and poor reproductive performance as well as reduced immune competence that increase susceptibility to diseases and prolonged recovery (Whitaker et al., 1993; Goff \& Horst, 1997; Drackley, 1999; Kehrli et al., 1999). Therefore, this study focused on evaluating the clinical and serum biochemical changes particularly those related to lipid metabolism such as LCAT and apoB-100 during the transition period in healthy and diseased Holstein dairy cattle and proving their diagnostic significance as predictors of periparturient diseases.

\section{MATERIALS AND METHODS}

\section{Animals}

This study was conducted on Holstein dairy cattle $(n=80)$ belonging to dairy farms of Rakuno Gakuen University and Matshimora dairy farms in Ebetsu city, Hokkaido area, Japan. These cows were examined during the transition period at two different times; one is before calving during the close-up period: from -4 to -14 DIM (days in milk) and the other after calving during the post-fresh period: between 1 and 50 DIM. The examined cows were classified into 2 main groups: healthy control cows $(n=61)$ and diseased cows $(n=19)$. The diseased cows were classified as diseased after calving (1 to 50 DIM). All cattle were treated under the Laboratory Animal Control Guidelines of Rakuno Gakuen University, which basi- 
Changes in clinical and blood lipid metabolism parameters in Holstein dairy cattle during ...

cally conform to the Guide for the Care and Use of Laboratory Animals of the National Institutes of Health in the USA (NIH publication No. 86-23, rev. 1996).

\section{Samples}

All blood samples were obtained from the tail vein. Whole blood samples were collected with EDTA and stored at $4{ }^{\circ} \mathrm{C}$ until analysis. Samples collected in plain vacutainer tubes were then centrifuged at $3000 \mathrm{rpm}$ for $15 \mathrm{~min}$. Sera were separated and stored at $-20{ }^{\circ} \mathrm{C}$ till analysis.

\section{Methods}

Clinical examination and estimation of serum biochemicals were conducted twice; at close-up ( -4 to -14 DIM) and post-fresh (1 to 50 DIM). Clinical examination of all dairy cattle was done using a clinical chart (Rosenberger, 1990). Body condition score (BCS) of all cows was estimated based on a 5-point scale (Ferguson et al., 1994).

Total plasma proteins were estimated by refractometry. PCV was measured by using the microhaematocrit method (Coles, 1986).

LCAT activity was determined spectrophotometrically with commercial kits (Sekisui medical, Tokyo, Japan) as per Uchida et al. (1995). Serum apoB-100 concentrations were estimated using single radial immunodiffusion assay and commercial kits (Bovis ApoB plate, the institute for metabolic Ecosystem, Osaka, Japan) according to Oikawa \& Katoh (2002). Serum NEFAs (NEFA C, Wako Chemicals $\mathrm{GmbH}$, Neuss, Germany) and blood glucose (Glucose, HK, Konelab, Thermo Electron Corporation) were determined on a Konelab 30 chemistry analyser (Thermo Electron Corporation). Serum NEFA and glucose were measured at Kishimoto Clinical Laboratory, Sapporo, Japan.

\section{Statistical analysis}

All statistical analyses were performed using computer software (SPSS version 17.0, Chicago, USA). The data obtained were analysed by independent-sample or paired $t$-test. The significance of differences between the means at control group and diseased group either in close-up period or post-fresh period was evaluated by Dunnett's test. Values were expressed as means $\pm \mathrm{SD}$.

\section{RESULTS}

The most common diseases of transition periods that were reported at the first 50 DIM in dairy cattle included retained placenta, ketosis, DA, milk fever, mastitis and dystocia. Retained placenta, ketosis and DA i.e. energy related diseases were sometimes associated with one or more diseases states such as milk fever, mastitis and dystocia.

During this study, clinical examinations revealed that the temperature, pulse and respiration showed no remarkable changes during the current study either in control or diseased cattle. The rumen movements were reduced in most of the diseased cases. Signs of dehydration were not observed in any of the examined cows.

BCS was significantly $(\mathrm{P}<0.05)$ reduced in post-fresh control cows when their values were compared with those of closeup control period. These remarkable changes were not reported between the diseased cattle. BCS was not remarkably changed in close-up or post-fresh periods when its values in control cattle were compared with those of diseased one, but BCS was still within the physiological reference values in control and diseased cattle (Table 1). 
Serum LCAT activities and concentrations of apoB-100 were not considerably changed in cattle between close up and post-fresh periods either in healthy cows or in diseased one. On the other hand, although serum apoB-100 concentrations were within the normal physiological reference values in both control and diseased cattle, they were lower than normal reference values in $9.83 \%$ of the control group and in $26.32 \%$ of the diseased group.

Serum LCAT activities $(\mathrm{P}<0.01)$ and apoB-100 levels $(\mathrm{P}<0.05)$ were very reduced in close-up diseased cattle vs close-up controls. Serum LCAT activities were also remarkably $(\mathrm{P}<0.01)$ reduced in post-fresh diseased cattle compared to those of post-fresh control ones, while serum apoB-100 showed no significant changes between control and diseased groups at post-fresh period (Table 1).

Blood glucose and PCV were significantly $(\mathrm{P}<0.05)$ decreased in post-fresh control cows than in the close-up control group. Total plasma proteins were significantly $(\mathrm{P}<0.05)$ increased in post-fresh control cows when their values were compared with those of close-up control group. Such changes were not reported for blood glucose, total proteins and PCV between close-up and post-fresh diseased cattle. Blood glucose, total proteins and PCV were still within the physiological reference values in both groups (control and diseased cows) during the period before and after calving. Blood glucose concentrations (Table 1) were substantially $(\mathrm{P}<0.05)$ reduced in close-up diseased animals compared with close-up

Table 1. Mean values of body condition score (BCS) and blood lecithin cholesterol acyltransferase (LCAT), apolipoprotein B-100 (ApoB-100), non-esterified fatty acids (NEFA), glucose (GLU), total protein (TP) and packed cell volume (PCV) in cattle during the transition period

\begin{tabular}{lcccc}
\hline & \multicolumn{2}{c}{ Close up cattle } & \multicolumn{2}{c}{ Post-fresh cattle } \\
\cline { 2 - 5 } & \multicolumn{1}{c}{ Control } & Diseased & Control & Diseased \\
\hline $\begin{array}{l}\text { BCS } \\
(2.5-4)^{1}\end{array}$ & $3.39 \pm 0.23$ & $3.11 \pm 0.29$ & $3.23 \pm 0.24$ & $3.01 \pm 0.34$ \\
\hline $\begin{array}{l}\text { LCAT }(\mathrm{U}) \\
(929-1059)^{2}\end{array}$ & $891.25 \pm 123.79$ & $386.19 \pm 87.71^{* *}$ & $898.39 \pm 120.89$ & $403.04 \pm 90.21^{* *}$ \\
\hline $\begin{array}{l}\text { ApoB-100 }(\mathrm{g} / \mathrm{L}) \\
(0.01-0.2)^{3}\end{array}$ & $0.18 \pm 0.08$ & $0.13 \pm 0.08^{*}$ & $0.17 \pm 0.07$ & $0.17 \pm 0.10$ \\
\hline $\begin{array}{l}\text { NEFA }(\mathrm{mmol} / \mathrm{L}) \\
(0.21-0.62)^{4}\end{array}$ & $0.22 \pm 0.17$ & $0.17 \pm 0.11$ & - & - \\
\hline $\begin{array}{l}\text { GLU }(\mathrm{mmol} / \mathrm{L}) \\
(4.50-6.71)^{5}\end{array}$ & $6.08 \pm 0.71$ & $5.47 \pm 0.57^{*}$ & $5.04 \pm 1.04$ & $4.89 \pm 0.70$ \\
\hline $\begin{array}{l}\text { TP }(\mathrm{g} / \mathrm{L}) \\
(57-81)^{6}\end{array}$ & $63.98 \pm 4.22$ & $64.94 \pm 5.92$ & $65.95 \pm 5.11$ & $68.00 \pm 4.00$ \\
\hline $\begin{array}{l}\text { PCV }(\%) \\
(30-40)^{7}\end{array}$ & $30.58 \pm 1.74$ & $31.37 \pm 2.01$ & $29.18 \pm 2.36$ & $30.37 \pm 4.50$ \\
\hline
\end{tabular}

$* \mathrm{P}<0.05 ; * * \mathrm{P}<0.01$ vs control animals. Reference values according to: ${ }^{1}$ Furgson et al. $(1994),{ }^{2} \mathrm{Naka}-$ gawa \& Katoh (1998), ${ }^{3}$ Mahley et al. (1984), ${ }^{4}$ Oikawa \& Katoh (2002), ${ }^{5}$ Zadnik (2003), ${ }^{6}$ Radostits et al. (2000), ${ }^{7}$ Rosenberger (1990). 
Changes in clinical and blood lipid metabolism parameters in Holstein dairy cattle during ...

control ones. Blood glucose showed no significant changes between control and diseased cows at post-fresh period. On the other hand, total proteins and PCV were not significantly changed in both close-up and post-fresh periods.

Serum NEFA (Table 1) showed no significant changes at the close-up period between healthy and diseased cows and were within the physiological reference ranges.

\section{DISCUSSION}

The current study mentioned that the most common diseases of transition periods that were reported at the first 50 DIM in dairy cattle included retained placenta, ketosis, The retained placenta, ketosis and DA (energy related diseases) were reported to be occasionally associated with one or more of milk fever, mastitis and dystocia. Kehrli et al. (1999) added that maladaptive response to negative energy balance (NEB) and other stressors during periparturient period may be associated with impaired immune function resulting in increased susceptibility to different diseases such as metritis, retained placenta, DA.

Clinical examination revealed no remarkable changes during the current study neither in control nor in diseased cattle. They were within the physiological reference values as reported by Rosenberger (1990). Some other studies mentioned different clinical findings associated with diseases of transition cows such as those related to DA cases where diseased cows with DA were febrile with increased heart and respiratory rates and reduced ruminal movements (El-Attar et al., 2007). Ketosis has been found to be associated with a gradual loss in body condition over several days or even weeks and a moderate to marked decline in milk yield over five to six days before the onset of obvious clinical signs (Edwards \& Tozer, 2004) which can persist (up to 5 liters per day) for up to two weeks after diagnosis (Rajala-Schultz et al., 1999).

The results of this study showed that BCS was significantly reduced in postfresh control cows when their values were compared with those of close-up ones. This value is still considered within the physiological references in dairy cows, as mentioned by Ferguson et al. (1994). This change in BCS values was not noticed in diseased cattle. Also no changes were reported between control and diseased cow either during close-up or post-fresh periods. Previous studies reported that most dairy cows face NEB in early lactation; postpartum feed intake is lower in cows with higher BCS prepartum, leaving them in NEB for a longer period than cows with normal or low BCS (Hayirli et al., 2002). Edwards \& Tozer (2004) reported that ketosis was usually associated with gradual loss of body condition over several days or even weeks.

The results showed that serum LCAT activities and concentrations of apoB-100 were not remarkably changed between close-up and post-fresh periods either in healthy cows or in diseased one. Serum LCAT activities were reported to be within the normal physiological range in all healthy cows (Nakagawa \& Katoh, 1998; Katoh, 2002). Nakagawa \& Katoh (1998) reported that serum LCAT activities in cows with ketosis and in those with LDA were significantly decreased compared to those in healthy cows. On the other hand, although serum apoB-100 concentrations were within the normal physiological reference values that were mentioned by Mahley et al. (1984) in some control or diseased cattle, they were lower than normal reference values in 
$9.83 \%$ of the control cattle and in $26.32 \%$ of the diseased group. Previous reports mentioned that the apoB-100 concentration is low during early lactation, relative to the other stages (Yamamoto et al., 1995). The decreased apoB-100 concentrations are similar among all diseased cows and also in 40 to $60 \%$ of healthy controls during early lactation and, moreover, are not largely different from those in cows with fatty liver (Gerloff et al., 1986; Herdt, 1988). The present study also revealed that serum LCAT activities and concentrations of apoB-100 were markedly reduced in diseased cattle at close-up period when their values were compared to those in diseased cattle. The previous reports indicated that LCAT activity, together with the cholesteryl ester concentration, was decreased in cows affected with ketosis and LDA (Nakagawa \& Katoh, 1998) and with milk fever (Nakagawa \& Katoh, 2000). The apoB100 concentration is decreased in cows with ketosis, LDA, retained placenta (Oikawa et al., 1997) or milk fever (Oikawa $\&$ Katoh, 2002). The current work found that serum LCAT activities were also remarkably reduced in diseased cattle at post-fresh period compared to those of the control ones while serum apoB-100 showed no significant changes between control and diseased groups at post-fresh period. These results are in line with those of Nakagawa \& Katoh (2000) who confirmed that the reduction in LCAT activity was detected prior to the occurrence of ketosis or milk fever. They also mentioned that as a diagnostic marker for fatty liver-related diseases, LCAT activity is more useful than apoB-100 and apolipoprotein C-III concentrations because the reduction precedes clinical signs such as ketonuria or recumbency and also because the activity is not altered during the peripartum period, at least in some healthy cows.

Blood glucose and PCV were significantly decreased in post-fresh control cows compared to close-up ones. These remarkable changes were not reported in the diseased cattle. However, blood glucose and PCV values in all examined cattle were still within the physiological reference values that were reported by Zadnik (2003) and Rosenberger (1990), respectively. The obtained results in this study also stated that blood glucose concentrations were significantly reduced in the diseased cows when their values were compared to those of the control group in the close-up period. These changes were not reported between control and the diseased cows at post-fresh period. Some other literature reports revealed that glucose concentration is reduced and NEFA concentration is increased during the prepartum period in primiparous cows that developed clinical mastitis in the postpartum period compared to healthy cows (Schwegler et al., 2013). Moyes et al. (2009) observed that a higher prepartum glucose concentration is associated with the occurrence of postpartum diseases. Blood glucose concentrations in cows with subclinical ketosis (SCK) were significantly lower than in cows without SCK (Sakha et al., 2007). $\mathrm{PCV}$, haemoglobin and serum iron are consistently higher in non-lactating cows than in lactating cows. PCV varies with lactation stage, being highest in dry cows and lowest in early lactation (Radostits et al., 2007). Mokhber Dezfouli et al. (2013) reported that haemoglobin, $\mathrm{PCV}$, total leukocyes, neutrophils and total protein concentrations were significantly increased in the LDA cases compared to the control group. The present study found that total proteins were significantly 
Changes in clinical and blood lipid metabolism parameters in Holstein dairy cattle during ...

increased in post-fresh control cows compared to those of the close-up period. Such changes were not reported in diseased cattle. The total proteins values in control and diseased cattle in the current study were still within the physiological reference values which were similar to those reported by Radostits et al. (2000). On the other hand, total proteins in the present study had not significantly changed between control and diseased cattle neither in close-up nor in post-fresh periods. In contrast, the concentrations of total proteins and globulins were significantly higher in cows with clinical ketosis compared with those in healthy cattle (Yameogo et al., 2008). Wolter (1992) mentioned that ketosis is characterised by a liver steatosis which causes hypoproteinaemia. Mokhber Dezfouli et al. (2013) reported that total protein and glucose concentrations were significantly higher in the LDA cases compared to controls.

In this study, serum NEFA showed no significant changes at the close-up period between healthy and diseased cows. Serum NEFA concentrations in all examined dairy cattle were within the physiological reference ranges which is close to the results reported by Oikawa \& Katoh (2002). Elevated NEFA concentration in plasma is a prerequisite for development of hepatic lipidosis that occurs in DA cows (Rehage et al., 1996). Schwegler et al. (2013) reported a reduced serum glucose concentration and increased serum NEFA concentration during the prepartum period in primiparous cows that developed clinical mastitis in the postpartum period compared to healthy cows. Cameron et al. (1998) stated that NEB is expected in milking cows, so blood NEFA levels are high after calving and can be hardly evaluated.
The study concluded that serum LCAT activities were a highly sensitive indicator (diagnostic marker) of the transition period. Further, it was of a higher predictive value and hence diagnostic relevance than the other studied lipid metabolism profile indicators such as apoB-100, glucose and NEFA, in diseases of the transition period. The changes in serum LCAT activities were of high diagnostic importance as they enabled the cattle practitioners to anticipate metabolic diseases and to establish certain nutritional, management and medical strategies to avoid their occurrence.

\section{ACKNOWLEDGEMENTS}

The authors are grateful to both of Ministry of Higher Education in Egypt and staff members of Herd Health Department, School of Veterinary Medicine, Rakuno Gakuen University, Ebetsu, Hokkaido, Japan, for their kind support during conducting this study.

\section{REFERENCES}

Cameron, R. E. B., P. B. Dyk, T. H. Herdt, J. B. Kaneene, R. Miller, H. F. Bucholtz, J. S. Liesman, M. J. Vandehaar \& R. S. Emery, 1998. Dry cow diet, management, and energy balance as risk factors for displaced abomasum in high producing dairy herds. Journal of Dairy Science, 8, 132-139.

Coles, E. H, 1986. Collection of blood samples. In: Veterinary Clinical Pathology, $4^{\text {th }}$ edn, W. B. Saunders Company, Philadelphia, pp. 46-47.

Cook, N. B. \& K. V. Nordlund, 2004. Behavioral needs of the transition cow and considerations for special needs facility design. Veterinary Clinics of North America: Food Animal Practice, 20, 495-520.

Corohn, Y. T., 1998. Epidemiology of metabolic disorder in the parturient dairy cows. Journal of Dairy Science, 9, 2557. 
Drackley, J. R., 1999. Biology of dairy cows during the transition period: The final frontier? Journal of Dairy Science, 82, 2259-2273.

Edwards, J. L. \& P. R. Tozer, 2004. Using activity and milk yield as predictors of fresh cow disorders. Journal of Dairy Science, 87, 524-531.

El-Attar, H. M., M. Yassein, Abd El-Raof \& M. M. Ghanem, 2007. Alterations in the clinical, hematological and biochemical pictures in abomasal displacement in cows in Egypt. Veterinary Medical Journal, 16, 102-109.

Ferguson, J. D., D. T. Galligan \& N. Thomsen, 1994. Principal descriptors of body condition score in Holstein cows. Journal of Dairy Science, 77, 2695-2703.

Gerloff, B. J., T. H. Herdt \& R. S. Emery, 1986. Relationship of hepatic lipidosis to health and performance in dairy cattle. Journal of the American Veterinary Medical Association, 188, 845-850.

Goff, J. P. \& R. L. Horst, 1997. Physiological changes at parturition and their relationship to metabolic disorders. Journal of Dairy Science, 80, 1260-1268.

Hayirli, A., R. R. Grummer, E. V. Nordheim \& P. M. Crump, 2002. Animal and dietary factors affecting feed intake during the prefresh transition period in Holsteins. Journal of Dairy Science, 85, 3430-3443.

Herdt, T. H., 1988. Fatty liver in dairy cows. Veterinary Clinics of North America: Food Animal Practice, 4, 269-287.

Katoh, N., 2002. Relevance of apolipoproteins in the development of fatty liver and fatty liver-related peripartum diseases in dairy cows. Journal of Veterinary Medical Science, 64, 293-307.

Kehrli, M. E., K. Kimura, J. P. Goff, J. R. Stabel \& B. J. Nonnecke, 1999. Immunological dysfunction in periparturient cows - What role does it play in postpartum infectious diseases? In: Proceedings of the Annual Conference of the American Association of Bovine Practitioners, 32, 24-28.
LeBlanc, S. J., K. E. Leslie \& T. F. Duffield, 2005. Metabolic predictors of displaced abomasum in dairy cattle. Journal of Dairy Science, 88, 159-170.

Mahley, R. W., T. L. Innerarity, S. C. Rall \& K. H. Weisgraber, 1984. Plasma lipoproteins: Apolipoprotein structure and function. Journal of Lipid Research, 25, 1277-1294.

Mokhber Dezfouli, M., Z. Eftekhari, S. Sadeghian, A. Bahounar \& M. Jeloudari, 2013. Evaluation of hematological and biochemical profiles on dairy cows with left displacement of the abomasum. Comparative Clinical Pathology, 22, 175-179.

Moyes, K. M., T. Larsen, N. C. Friggens, J. K. Drackley \& K. L. Ingvartsen, 2009. Identification of potential markers in blood for the development of subclinical and clinical mastitis in dairy cattle at parturition and during early lactation. Journal of Dairy Science, 92, 5419-5428.

Nakagawa, H. \& N. Katoh, 1998. Reduced activity of lecithin:cholesterol acyltransferase in the serum of cows with ketosis and left displacement of the abomasum. Veterinary Research Communication, 22, $517-$ 524.

Nakagawa, H. \& N. Katoh, 2000. Reduction in serum lecithin:cholesterol acyltransferase activity prior to the occurrence of ketosis and milk fever in cows. Journal of Veterinary Medical Science, 62, 1263-1267.

Oikawa, S. \& N. Katoh, 2002. Decreases in apolipoprotein B-100 and A-I concentrations in cows with milk fever and downer cows. Canadian Journal of Veterinary Research, 66, 31-34.

Oikawa, S., N. Katoh, F. Kawawa \& O. Yasushi, 1997. Decreased serum apolipoprotein B-100 and A-I concentrations in cows with ketosis and left displacement of the abomasum. American Journal of Veterinary Research, 58, 121-125.

Radostits, O. M., C. C. Gay, D. C. Blood \& K. W. Hinchcliff, 2000. Veterinary Medicine: A Textbook of the Diseases of Cattle, Horses, Sheep, Pigs, and Goats, $9^{\text {th }}$ edn., W. B. Saunders, London. 
Changes in clinical and blood lipid metabolism parameters in Holstein dairy cattle during ...

Radostits, O. M., C. C. Gay, K. W. Hinchcliff \& P. D. Constable, 2007. Veterinary Medicine: A Textbook of the Diseases of Cattle, Horses, Sheep, Pigs, and Goats, $10^{\text {th }}$ edn., Saunders Elsevier, London.

Rajala-Schultz, P. J., Y. T. Gröhn \& C. E. McCulloch, 1999. Effects of milk fever, ketosis and lameness on milk yield in dairy cows. Journal of Dairy Science, 82, 288294.

Rehage, J., M. Mertens, N. StockhofeZurwieden, M. Kaske \& H. Scholz, 1996. Post surgical convalescence of dairy cows with left abomasal displacement in relation to fatty liver. Schweizer Archiv für Tierheilkunde, 138, 361-368.

Rosenberger, G., 1990. Die Klinische Untersuchung des Rindes: 3. Auflage herausgegeben, eds G. von Dirksen, H. D. Gründer \& M. S. Stöber, Verlag Paul Parey, Berlin and Hamburg, pp. 670-677.

Sakha, M., M. Ameri \& A. Rohbakhsh, 2006. Changes in blood $\beta$-hydroxybutyrate and glucose concentrations during dry and lactation periods in Iranian Holstein cows. Comparative Clinical Pathology, 15, 221-226.

Sakha, M., M. Ameri, H. Sharifi \& I. Taheri, 2007. Bovine subclinical ketosis in dairy herds in Iran. Veterinary Research Communication, 31, 673-679.

Schwegler, E., A. Schneider, P. Montagner, D. A. Acosta, L. F. Pfeifer, E. Schmitt, V. R. Rabassa, F. A. Del Pino, H. de Lima Gonzalez, C. D. Timm \& M. N. Corrêa, 2013. Predictive value of prepartum serum metabolites for incidence of clinical and subclinical mastitis in grazing primiparous Holstein cows. Tropical Animal Health and Production, 45, 1549-1555.

Uchida, E., N. Katoh \& K. Takahashi, 1995. The activity of lecithin: cholesterol acyltransferase in the serum of cows at parturition or with fatty liver. Veterinary Research Communication, 19, 343-351.

Whitaker, D. A., E. J. Smith, G. O. da Rosa \& J. M. Kelly, 1993. Some effects of nutrition and management on the fertility of dairy cattle. The Veterinary Record, $\mathbf{1 3 3}$, 61-64.

Wolter, R., 1992. Alimentation des vaches laitières, Agricultural Edition. Paris, France.

Yamamoto, O., S. Oikawa \& N. Katoh, 1995. Enzyme-linked immunosorbent assay for serum apolipoprotein B-100, a major triglyceride-transport protein in dairy cows. American Journal of Veterinary Research, 56, 1413-1417.

Yameogo, Y., G. A. Ouedraogo, C. Kanyandekwe \& G. J. Sawadogo, 2008. Relationship between ketosis and dairy cows' blood metabolites in intensive production farms of the periurban area of Dakar. Tropical Animal and Health Production, 40, 483-490.

Zadnik, T. A., 2003. Comparative study of the hematobiochemical parameters between clinically healthy cows and cows with displacement of the abomasum. Acta Veterinaria Belgrade, 53, 297-309.

Paper received 31.10.2016; accepted for publication 25.11.2016

\section{Correspondence:}

Arafat Khalphallah, DVM, PhD

Department of Animal Medicine, Faculty of Veterinary Medicine,

Assiut University,

Assiut 71526, Egypt

tel: +2021283888020 ,

fax: +20882366503 ,

email: arafatvet2003@yahoo.com 